\title{
Vitamin E Is a Nephroprotectant Agent in Male but Not in Female in a Model of Cisplatin-Induced Nephrotoxicity
}

\author{
Sima Jilanchi, ${ }^{1,2}$ Mehdi Nematbakhsh, ${ }^{1,3,4}$ Mehrnoosh Bahadorani, ${ }^{2}$ Ardeshir Talebi, ${ }^{1,5}$ \\ Fatemeh Eshraghi-Jazi, ${ }^{1}$ Azam Mansouri, ${ }^{1}$ and Farzaneh Ashrafi ${ }^{1,6}$ \\ ${ }^{1}$ Water \& Electrolytes Research Center, Isfahan University of Medical Sciences, Isfahan 81745, Iran \\ ${ }^{2}$ Deparment of Biology, Falavarjan Branch, Islamic Azad University, Isfahan 84515, Iran \\ ${ }^{3}$ Department of Physiology, Isfahan University of Medical Sciences, Isfahan 81745, Iran \\ ${ }^{4}$ Kidney Diseases Research Center, Isfahan University of Medical Sciences, Isfahan 81745, Iran \\ ${ }^{5}$ Department of Clinical Pathology, Isfahan University of Medical Sciences, Isfahan 81745, Iran \\ ${ }^{6}$ Department of Internal Medicine, Isfahan University of Medical Sciences, Isfahan 81745, Iran
}

Correspondence should be addressed to Mehdi Nematbakhsh; nematbakhsh@med.mui.ac.ir

Received 14 May 2013; Accepted 9 June 2013

Academic Editors: B. Di Iorio, E. F. Elsayed, C. Fourtounas, and G. Gonlusen

Copyright (C) 2013 Sima Jilanchi et al. This is an open access article distributed under the Creative Commons Attribution License, which permits unrestricted use, distribution, and reproduction in any medium, provided the original work is properly cited.

Background. The role of gender for nephroprotectant agent such as vitamin E in cisplatin- (CP-) induced nephrotoxicity has not been documented yet. Methods. One group from each gender of Wistar rats received a single dose of CP (7 mg/kg; i.p) and was treated with vitamin $\mathrm{E}$ ( $1 \mathrm{~g} / \mathrm{kg} /$ day) for 7 days, and they were compared with similar gender in the control group. Results. The serum levels of blood urea nitrogen $(\mathrm{BUN})$ and creatinine $(\mathrm{Cr})$ in male animals treated with $\mathrm{CP}$ was not different from the control group, but it was significantly different in the female rats $(P<0.05)$. The CP-induced damage intensity in male kidney tissue was not significantly different between the CP-treated and control groups, but this was not the case in female, indicating that the tissue damage in female is significantly different from the control group $(P<0.05)$. No significant difference in serum levels of magnesium $(\mathrm{Mg})$, nitrite, malondialdehyde (MDA), and lactate dehydrogenase (LDH) was seen between the genders. Kidney weight and body weight changes were statistically significant in both genders $(P<0.05)$. Significant difference was observed in uterus weight between the two groups of female $(P<0.05)$. Conclusion. Vitamin $\mathrm{E}$ may prevent $\mathrm{CP}$-induced nephrotoxicity in male, but possibly it has not such nephroprotectant effect in female.

\section{Introduction}

Cisplatin (CP) is an antitumor drug widely used in clinic [1]. This drug contains heavy metal platinum [2] and is used to treat a variety of neoplasms such as head, neck, testicular, ovarian, bladder, small cell lung, and esophagus cancers [3]. $\mathrm{CP}$ therapy produces free radicals such as superoxide and hydroxyl $[4,5]$ that lead to oxidative stress followed by nephrotoxicity, neurotoxicity, hepatotoxicity $[2,6]$, and endothelial dysfunction $[7,8]$. Kidney dysfunction causes glutathione depletion [9], decreases creatinine ( $\mathrm{Cr}$ ) clearance [10], and decreases the glomerular filtration rate $[11,12]$. To prevent $\mathrm{CP}-$ induced nephrotoxicity, renin angiotensin receptor antagonist (losartan) and different antioxidant substances have been suggested to be supplemented. L-arginine is the main precursor of nitric oxide (NO) in vascular endothelium, and its renoprotection role against $\mathrm{CP}$-induced nephrotoxicity was reported [13]. The effects of vitamins $\mathrm{C}$ and $\mathrm{E}$ on renal injury induced by CP have been reported previously. Vitamin C reduces free radicals in many biological processes [14] and protects the kidney against CP-induced oxidative stress [14]. Vitamin E, as a membrane stabilizer, is well known as free radical scavenger [15], and its nephroprotective role against CP-induced nephrotoxicity was previously reported [16-18]. Recently, the sex-based difference in kidney toxicity was the subject of researches $[17,19,20]$. Losartan as an angiotensin receptor-1 blocker and L-arginine provides different roles against CP-induced nephrotoxicity in male and female rats 
$[21,22]$. One study showed that vitamin $\mathrm{E}$ has no protective role against CP induced nephrotoxicity in ovarectomized female rat when pharmacological dose of estrogen was administrated [23]. Also, it has been reported that vitamin E has renoprotective effect against CP-induced nephrotoxicity in male rats, but the role of gender for nephroprotectant agent such as vitamin $\mathrm{E}$ in cisplatin (CP)-induced nephrotoxicity has not been reported yet $[24,25]$, Thus, we attempted to investigate the nephroprotective role of vitamin $\mathrm{E}$ in male and female rats.

\section{Materials and Methods}

2.1. Animals. Twelve adult female (weighting $177.7 \pm 2.4 \mathrm{~g}$ ) and fourteen adult male (weighting $199 \pm 3 \mathrm{~g}$ ) Wistar rats (Animal Center, Isfahan University of Medical Sciences, Isfahan, Iran) were used for this research. The rats were housed at the temperature of $23-25^{\circ} \mathrm{C}$. Rats had free access to water and rat chow. The rats were acclimatized to this diet for at least one week prior to the experiment. The experimental procedures were in advance approved by the Isfahan University Medical Sciences Ethics Committee.

2.2. Drugs. Vitamin E and CP (cis-diammineplatinum(II) dichloride, code p4394) were purchased from Sigma (St. Louis, MO, USA).

2.3. Experimental Protocol. Wistar rats were randomly assigned to four groups. The male animals in group $1(n=7)$ received a single dose of $\mathrm{CP}(7 \mathrm{mg} / \mathrm{kg})$ and then were treated with vitamin $\mathrm{E}(1 \mathrm{~g} / \mathrm{kg} /$ day $)$ for 7 days. The male animals in group $2(n=7)$ received the same regimen as group 1 , except vehicle (saline) instead of CP. Female animals in groups $3(n=$ $6)$ and $4(n=6)$ received regimen the same as groups 1 and 2 , respectively. The weight of animals was recorded on a daily basis. One week after CP injection, all animals were sacrificed after blood sampling. The serum was stored at $-20^{\circ} \mathrm{C}$ for the measurements. The kidneys and testis (or uterus in female) were excised and weighed immediately. The left kidney was used for histopathological investigations, and the right kidney was homogenized in $2 \mathrm{~mL}$ of saline and then centrifuged, and the supernatant was used for measurements.

2.4. Measurements. Serum levels of creatinine (Cr), blood urea nitrogen (BUN), lactate dehydrogenase (LDH), and magnesium $(\mathrm{Mg})$ were determined using quantitative diagnostic kits (Pars Azmoon, Iran). The serum level of nitrite (stable NO metabolite) was measured using a colorimetric assay kit (Promega Corporation, USA) that involves the Griess reaction. Serum and kidney levels of malondialdehyde (MDA) were quantified according to the manual method. Briefly, $500 \mu \mathrm{L}$ of the sample was mixed with $1000 \mu \mathrm{L}$ of $10 \%$ trichloroacetic acid (TCA). The mixture was vigorously shaken and centrifuged at $2000 \mathrm{~g}$ for $10 \mathrm{~min} ; 500 \mu \mathrm{L}$ of the supernatant was added to $500 \mu \mathrm{L}$ of $0.67 \%$ thiobarbituric acid (TBA). Then, the solution was incubated for $10 \mathrm{~min}$ in warm water bath at the temperature of $100^{\circ} \mathrm{C}$. After cooling, the absorbance was measured at the wavelength of $532 \mathrm{~nm}$.
2.4.1. Histopathological Procedures. For histopathological investigation, the excised left kidney was fixed in 10\% formalin solution, then was embedded in paraffin. The hematoxylin and eosin stain was used for assaying the tubular damage. Parameters of tubular damage included tubular dilation and simplification, tubular cells swelling and necrosis, tubular casts, and intraluminal cell debris with inflammatory cells infiltration that were considered in the pathological study. The intensity of tubular injuries was graded from 1 to 4 , while zero score was assigned to normal tissue without damage.

2.4.2. Statistical Analysis. Data are presented as mean \pm SEM. The quantitative data was compared separately between male and female groups using the unpaired Student's $t$-test. Due to the qualitative nature of the scoring, the Mann-Whitney test was applied to compare the pathology damage score between the groups. $P$ value $<0.05$ was considered statistically significant.

\section{Results}

The data are presented in Figures 1 and 2. The serum levels of BUN and Cr were significantly different in female $(P<0.05)$ but not in male. These findings indicated that vitamin $\mathrm{E}$ could not attenuate the increased serum levels of BUN and Cr in female. The pathology score data also reveals similar results, indicating the nephroprotective role of vitamin $\mathrm{E}$ in male but not in female (Figure 3). The normalized kidney weight and percentage of body weight change were significantly different in both genders $(P<0.05)$. However, vitamin $\mathrm{E}$ attenuated these data toward normal value in male more than female. No significant difference was observed in testis weight between the male groups, but the female groups were significantly different in the uterus weight $(P<0.05)$. No significant difference was observed in serum levels of $\mathrm{Mg}, \mathrm{LDH}$, nitrite, and MDA; and the kidney tissue level of nitrite and MDA was observed between the CP-treated and control groups in male or in female animals.

\section{Discussion}

The main objective of this research was to determine the role of gender in protective effect of vitamin E against CPinduced nephrotoxicity in the rat model. We showed the sexrelated effects of vitamin $\mathrm{E}$ on $\mathrm{CP}$-induced nephrotoxicity. $\mathrm{CP}$ reduced body weight in both male and female rats that may be related to disturbances in gastrointestinal or tubular absorption [26-28], as well as loss of skeletal muscle and apoptosis $[27,29]$. The weight loss was also confirmed by our previous studies [21, 23]. Administration of vitamin E ameliorated weight loss induced by CP in male but not in female. In agreement with results obtained in the present study, we previously have reported that L-arginine and losartan as supplements ameliorate weight loss only in CP-treated male animals [21, 22]. Administration of vitamin E normalized the increased serum levels of BUN and Cr only in male animals, possibly due to the antioxidant effects of vitamin $\mathrm{E}$ against $\mathrm{CP}$-induced nephrotoxicity mediated by oxidative stress. Vitamin E acts 


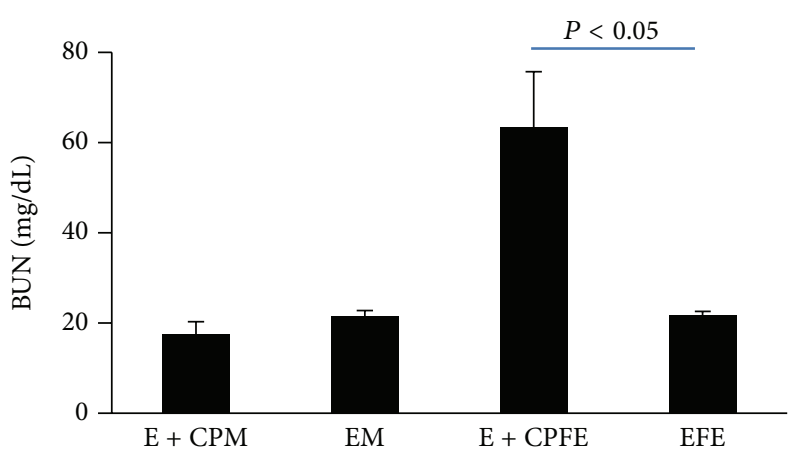

(a)

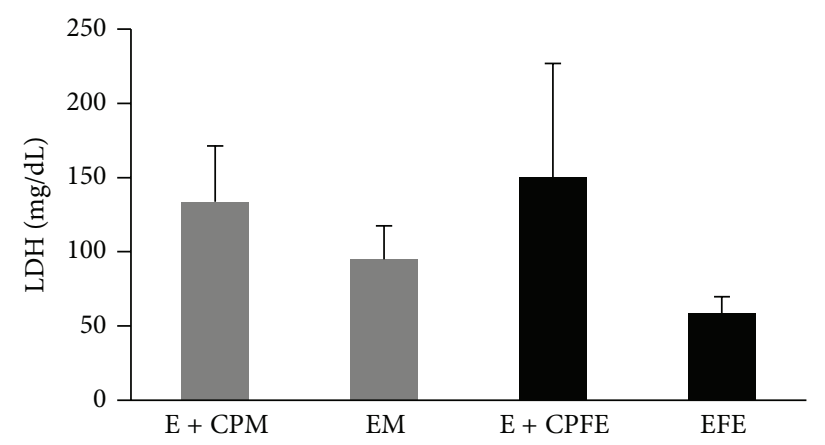

(c)

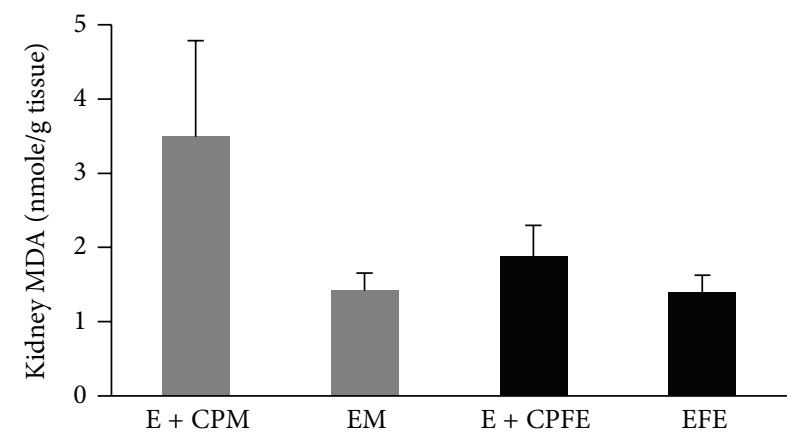

(e)

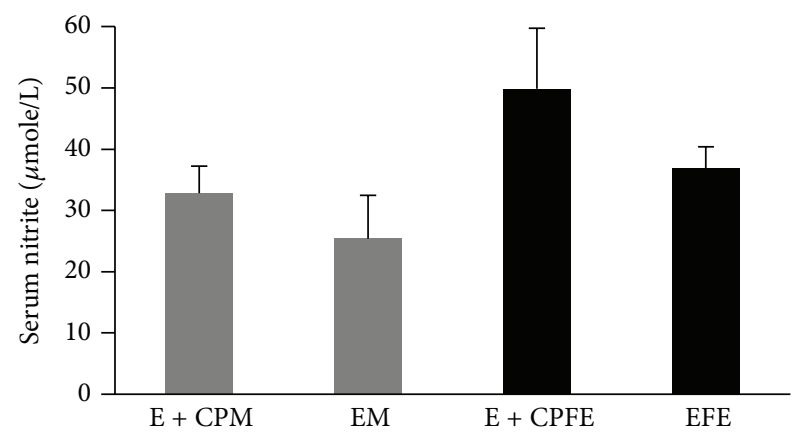

(g)

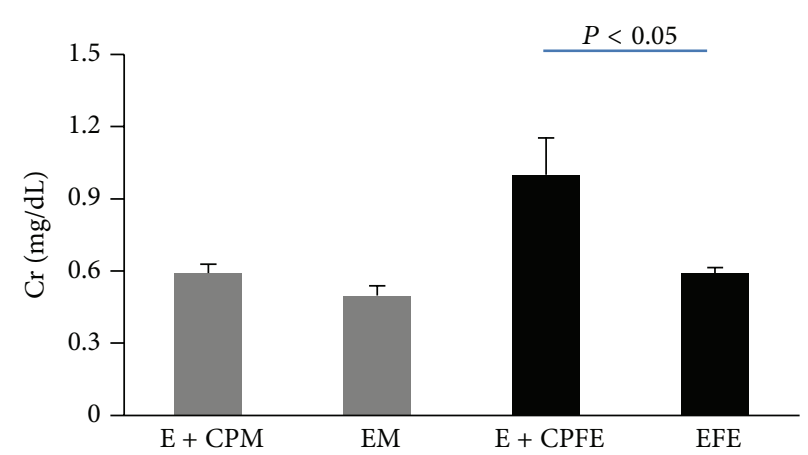

(b)

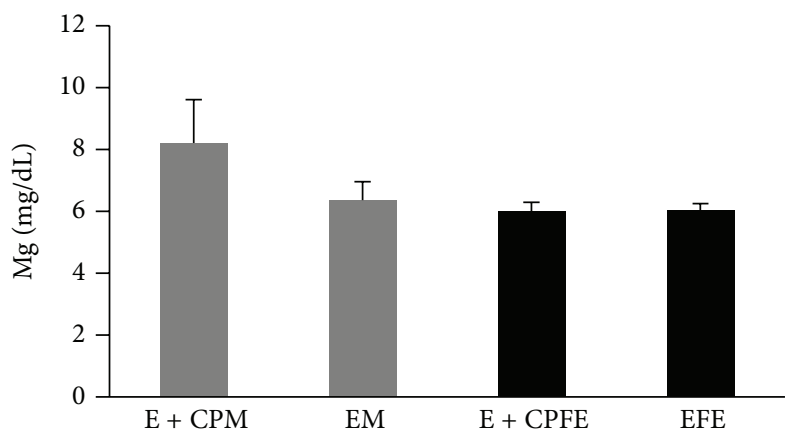

(d)

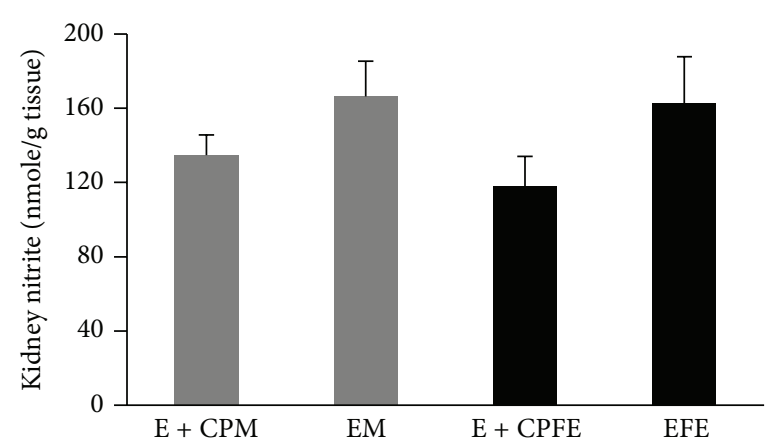

(f)

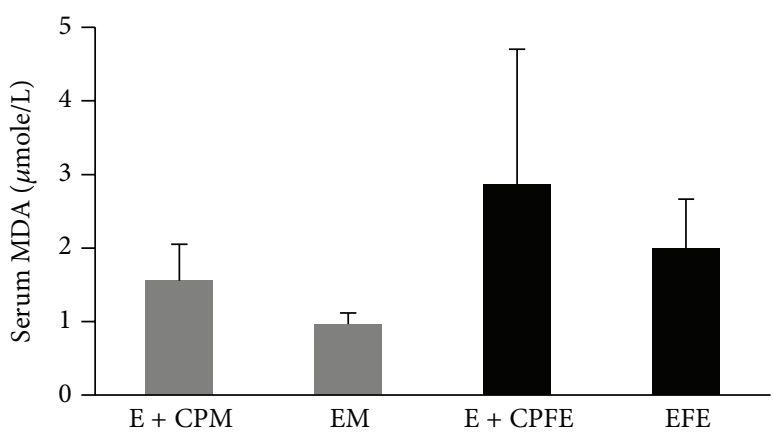

(h)

Figure 1: (a) Blood urea nitrogen (BUN), (b) creatinine, (c) lactate dehydrogenase (LDH), and (d) magnesium (Mg) levels in serum, (e) kidney tissue levels of malondialdehyde (MDA) and (f): nitrite, and serum levels of ( $g$ ) nitrite and (h) MDA in four experimental groups of animals treated with CP and vitamin E. E + CPM, E + CPFE, EM, and EFE stand for the group names: males treated with vitamin E and CP, females treated with vitamin $\mathrm{E}$ and $\mathrm{CP}$, males treated with vitamin $\mathrm{E}$ alone, and females treated with vitamin $\mathrm{E}$ alone, respectively. 


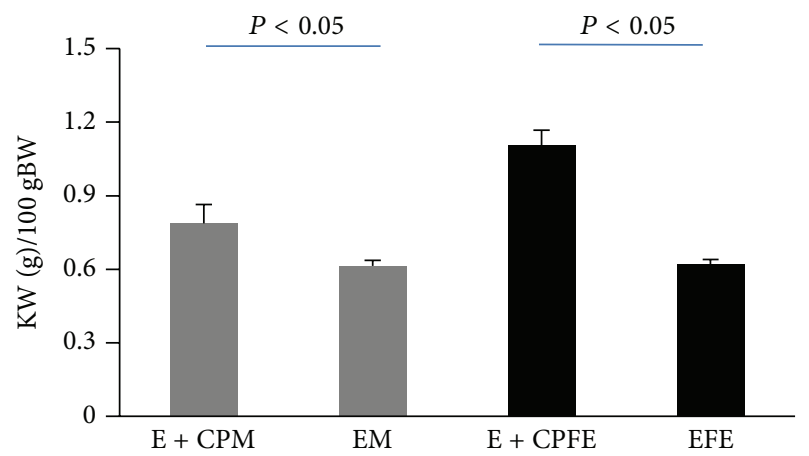

(a)

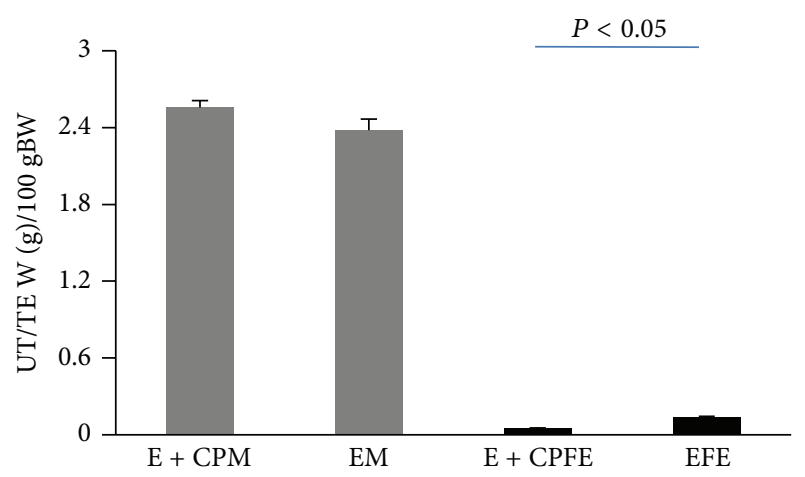

(c)

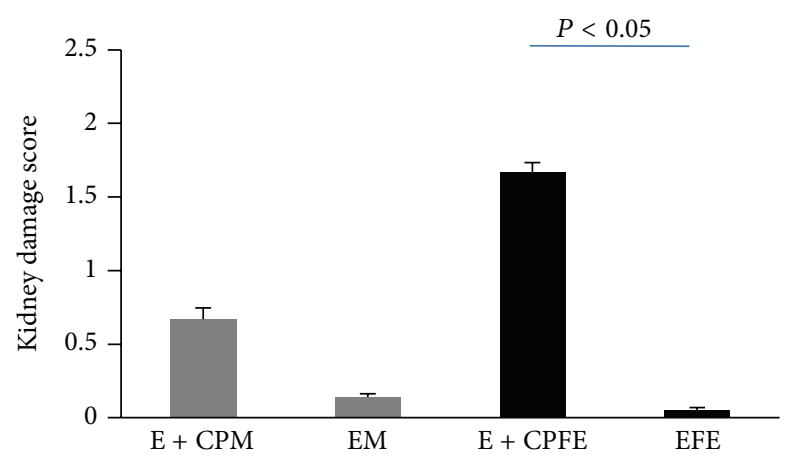

(b)

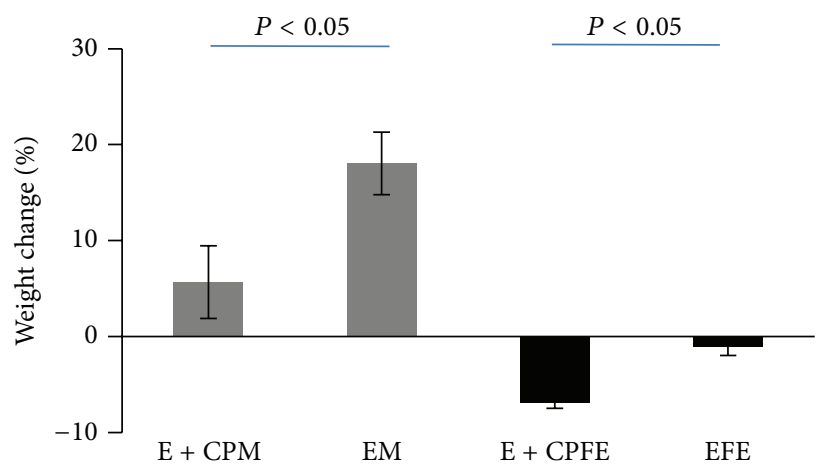

(d)

FiguRE 2: (a) Kidney weight (KW), (b) kidney damage score, (c) uterus/testis weight, and (d) percentage of weight change in four experimental groups of animals treated with CP and vitamin E. E + CPM, E + CPFE, EM, and EFE stand for the group names: males treated with vitamin $\mathrm{E}$ and $\mathrm{CP}$, females treated with vitamin $\mathrm{E}$ and $\mathrm{CP}$, males treated with vitamin $\mathrm{E}$ alone, and females treated with vitamin $\mathrm{E}$ alone, respectively.
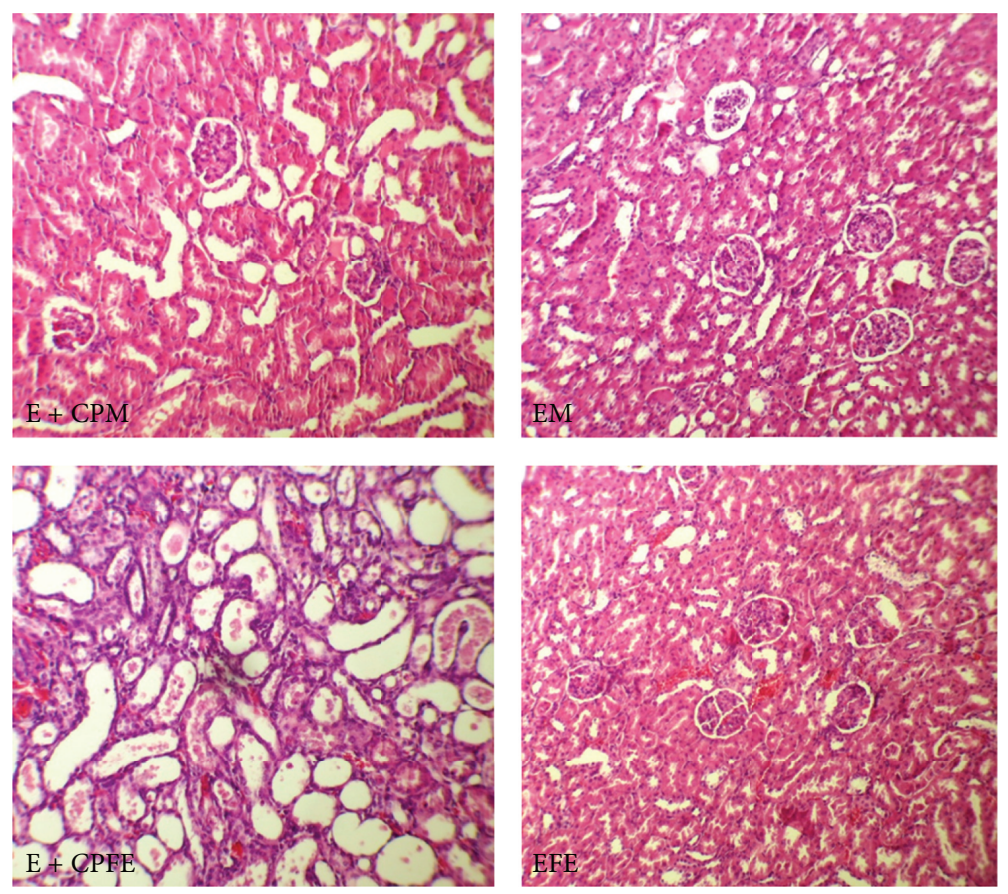

FIGURE 3: The images of kidney tissues (magnification $\times 100$ ) in all groups of experiments. $\mathrm{E}+\mathrm{CPM}, \mathrm{E}+\mathrm{CPFE}, \mathrm{EM}$, and EFE stand for the group names: males treated with vitamin $\mathrm{E}$ and $\mathrm{CP}$, females treated with vitamin $\mathrm{E}$ and $\mathrm{CP}$, males treated with vitamin $\mathrm{E}$ alone, and females treated with vitamin E alone, respectively. More kidney tissue damage was observed in groups E + CPFE. 
as free radical scavenger against stress oxidative [30]. CP induces oxidative renal damage, which results in production of free radicals and lipid peroxidation in tubular cells [5]. This was exhibited by nonsignificant elevated values of MDA in both sexes. Hypomagnesemia is one of the side effects of CP that occurs within two weeks after CP administration [31]. However, we did not observe $\mathrm{Mg}$ depletion in the current study, probably due to the duration of the study (one week). Histopathological investigations have demonstrated that $\mathrm{CP}$ administration reduces testis weight [32]. CP induces apoptosis in germ cells and Sertoli cells and also reduces the diameter of seminiferous tubules and serum level of testosterone [32]. Our findings showed that vitamin E prevented testicular weight reduction induced by $\mathrm{CP}$, and another study also showed that different levels of vitamin $\mathrm{E}$ in diet affect the testis indexes [33]. An evidence showed that vitamin E can protect ley dig cells against reactive oxygen species [33]. Furthermore, our study demonstrated that vitamin E could not inhibit reduction of uterus weight induced by CP. CP caused apoptosis and necrosis in uterus tissue [34], and it seems that CP interacts with female hormonal system [35]. Recently, we provided an evidence for unfavorable effect of estrogen on nephrotoxicity induced by $\mathrm{CP}$ in ovariectomized female rats [23], and when estrogen was accompanied by antioxidants such as vitamins $\mathrm{E}$ and $\mathrm{C}$ and losartan, renal failure was intensified [23]. Also, our previous studies indicated that L-arginine and losartan as supplements induce different responses in nephrotoxicity model induced by $\mathrm{CP}$ in both male and female rats [21, 23]. Involved mechanisms are not exactly known, but it is clear that sex hormones play an important role in CP-induced nephrotoxicity in female. Female sex hormone also induces production of nitric oxide [36]. Nitric oxide, as a vasodilator agent, involved in kidney circulation [37]. Coadministration of $\mathrm{CP}$ and vitamin $\mathrm{E}$ nonsignificantly increased the serum level of nitrite in both genders. In contrast, vitamin $\mathrm{E}$ accompanied by $\mathrm{CP}$ nonsignificantly decreased the kidney level of NO in both genders. It seems that both renal and serum levels of $\mathrm{NO}$ were affected by various mechanisms. $\mathrm{CP}$ induces endothelial dysfunction and increases iNOS level [38], and NO involved in CPinduced toxicity [39]. Elevation of serum levels of NO by $\mathrm{L}$-arginine enhanced CP-induced nephrotoxicity in female rats [21]. In this study, we observed elevated serum levels of nitrite in female more than male rats, probably due to the increasing iNOS level and presence of estrogen. It has been documented that estrogen itself induces oxidative stress [40] and promotes NO production.

\section{Conclusion}

It is concluded that vitamin $\mathrm{E}$ protects male gender against $\mathrm{CP}$-induced nephrotoxicity. However, it fails to prevent CPinduced nephrotoxicity in female. Also interaction of supplements with gender difference is not known, and it requires further investigations.

\section{Conflict of Interests}

The authors do not have any direct financial relationship with the commercial identities mentioned in this paper. So, the authors have no conflict of interests to declare.

\section{Acknowledgment}

This research was supported by the Isfahan University of Medical Sciences.

\section{References}

[1] L. Dalla Via, V. Di Noto, M. Vidali, F. Scomazzon, D. Ni, and R. Deana, "Action of antitumoral platinum complexes on in vitro platelet functions," Chemico-Biological Interactions, vol. 110, no. 3, pp. 203-220, 1998.

[2] J. Liu, Y. Liu, S. S. M. Habeebu, and C. D. Klaassen, "Metallothionein (MT)-null mice are sensitive to cisplatin-induced hepatotoxicity," Toxicology and Applied Pharmacology, vol. 149, no. 1, pp. 24-31, 1998.

[3] B. Rosenberg, "Charles F. Kettring prize. Fundamental studies with cisplatin," Cancer, vol. 55, no. 10, pp. 2303-2316, 1985.

[4] R. Baliga, Z. Zhang, M. Baliga, N. Ueda, and S. V. Shah, "In vitro and in vivo evidence suggesting a role for iron in cisplatininduced nephrotoxicity," Kidney International, vol. 53, no. 2, pp. 394-401, 1998.

[5] H. Matsushima, K. Yonemura, K. Ohishi, and A. Hishida, "The role of oxygen free radicals in cisplatin-induced acute renal failure in rats," Journal of Laboratory and Clinical Medicine, vol. 131, no. 6, pp. 518-526, 1998.

[6] Y. Sadzuka, T. Shoji, and Y. Takino, "Mechanism of the increase in lipid peroxide induced by cisplatin in the kidneys of rats," Toxicology Letters, vol. 62, no. 2-3, pp. 293-300, 1992.

[7] S. Kohn, M. Fradis, L. Podoshin, J. Ben-David, J. Zidan, and E. Robinson, "Endothelial injury of capillaries in the stria vascularis of guinea pigs treated with cisplatin and gentamicin," Ultrastructural Pathology, vol. 21, no. 3, pp. 289-299, 1997.

[8] H. Ito, T. Okafuji, and T. Suzuki, "Vitamin E prevents endothelial injury associated with cisplatin injection into the superior mesenteric artery of rats," Heart and Vessels, vol. 10, no. 4, pp. 178-184, 1995.

[9] J.-G. Zhang and W. E. Lindup, "Role of mitochondria in cisplatin-induced oxidative damage exhibited by rat renal cortical slices," Biochemical Pharmacology, vol. 45, no. 11, pp. 22152222, 1993.

[10] J. A. Gordon and V. H. Gattone II, "Mitochondrial alterations in cisplatin-induced acute renal failure," The American Journal of Physiology, vol. 250, no. 6, pp. F991-F998, 1986.

[11] P. M. Macleod, C. J. Tyrell, and D. H. Keeling, "The effect of cisplatin on renal function in patients with testicular tumours," Clinical Radiology, vol. 39, no. 2, pp. 190-192, 1988.

[12] G. Daugaard, U. Abildgaard, N. H. Holstein-Rathlou, P. Leyssac, O. Amtorp, and T. Dikhoff, "Acute effect of cisplatin on renal hemodynamics and tubular function in dog kidneys," Kidney and Blood Pressure Research, vol. 9, no. 5, pp. 308-316, 1986.

[13] S. Saleh and E. El-Demerdash, "Protective effects of L-arginine against cisplatin-induced renal oxidative stress and toxicity: role of nitric oxide," Basic and Clinical Pharmacology and Toxicology, vol. 97, no. 2, pp. 91-97, 2005. 
[14] D. Appenroth, S. Fröb, L. Kersten, F.-K. Splinter, and K. Winnefeld, "Protective effects of vitamin E and C on cisplatin nephrotoxicity in developing rats," Archives of Toxicology, vol. 71, no. 11, pp. 677-683, 1997.

[15] X. Wang and P. J. Quinn, "Vitamin E and its function in membranes," Progress in Lipid Research, vol. 38, no. 4, pp. 309-336, 1999.

[16] M. NazÄroÇlu, A. KaraoÄŸlu, and A. O. Aksoy, "Selenium and high dose vitamin $\mathrm{E}$ administration protects cisplatin-induced oxidative damage to renal, liver and lens tissues in rats," Toxicology, vol. 195, no. 2, pp. 221-230, 2004.

[17] S. Atasayar, H. Gürer-Orhan, H. Orhan, B. Gürel, G. Girgin, and H. Özgüneş, "Preventive effect of aminoguanidine compared to vitamin $\mathrm{E}$ and $\mathrm{C}$ on cisplatin-induced nephrotoxicity in rats," Experimental and Toxicologic Pathology, vol. 61, no. 1, pp. 23-32, 2009.

[18] M. Nematbakhsh, F. Ashrafi, T. Safari, A. Talebi, H. Nasri, M. Mortazavi et al., "Administration of vitamin E and losartan as prophylaxes in cisplatin-induced nephrotoxicity model in rats," Journal of Nephrology, vol. 25, no. 3, pp. 410-417, 2012.

[19] Y. O. Ilbey, E. Ozbek, M. Cekmen, A. Simsek, A. Otunctemur, and A. Somay, "Protective effect of curcumin in cisplatininduced oxidative injury in rat testis: mitogen-activated protein kinase and nuclear factor-kappa B signaling pathways," Human Reproduction, vol. 24, no. 7, pp. 1717-1725, 2009.

[20] Q. He, C. H. Liang, and S. J. Lippard, "Steroid hormones induce HMG1 overexpression and sensitize breast cancer cells to cisplatin and carboplatin," Proceedings of the National Academy of Sciences of the United States of America, vol. 97, no. 11, pp. 5768$5772,2000$.

[21] F. Eshraghi-Jazi, M. Nematbakhsh, H. Nasri et al., "The protective role of endogenous nitric oxide donor (L-arginine) in cisplatin-induced nephrotoxicity: gender related differences in rat model," Journal of Research in Medical Sciences, vol. 16, no. 11, pp. 1389-1396, 2011.

[22] M. Haghighi, M. Nematbakhsh, A. Talebi, H. Nasri, F. Ashrafi, K. Roshanaei et al., "The role of angiotensin II receptor 1 (AT1) blockade in cisplatin-induced nephrotoxicity in rats: genderrelated differences," Renal Failure, vol. 34, no. 8, pp. 1046-1051, 2012.

[23] M. Nematbakhsh, Z. Pezeshki, F. Eshraghi-Jazi, F. Ashrafi, H. Nasri, A. Talebi et al., "Vitamin E, Vitamin C, or Losartan is not nephroprotectant against cisplatin-induced nephrotoxicity in presence of estrogen in ovariectomized rat model," International Journal of Nephrology, vol. 2012, Article ID 284896, 2012.

[24] D. Stakisiaitis, G. Dude-niene, R. J. Jankunas, G. Grazeliene, J. Didziapetriene, and B. Pundziene, "Cisplatin increases urinary sodium excretion in rats: gender-related differences," Medicina, vol. 46 , no. 1 , pp. $45-50$.

[25] Q. Wei, M.-H. Wang, and Z. Dong, "Differential gender differences in ischemic and nephrotoxic acute renal failure," The American Journal of Nephrology, vol. 25, no. 5, pp. 491-499, 2005.

[26] U. Ammer, Y. Natochin, C. David, G. Rumrich, and K. J. Ullrich, "Cisplatin nephrotoxicity: site of functional disturbance and correlation to loss of body weight," Renal Physiology and Biochemistry, vol. 16, no. 3, pp. 131-145, 1993.

[27] H. I. El-Sayyad, M. F. Ismail, F. M. Shalaby et al., "Histopathological effects of cisplatin, doxorubicin and 5-flurouracil (5-FU) on the liver of male albino rats," International Journal of Biological Sciences, vol. 5, no. 5, pp. 466-473, 2009.
[28] T. Ohno, S. Kato, M. Wakatsuki et al., "Incidence and temporal pattern of anorexia, diarrhea, weight loss, and leukopenia in patients with cervical cancer treated with concurrent radiation therapy and weekly cisplatin: comparison with radiation therapy alone," Gynecologic Oncology, vol. 103, no. 1, pp. 94-99, 2006.

[29] K. V. Kumar, A. A. Shifow, M. U. R. Naidu, and K. S. Ratnakar, "Carvedilol: a beta blocker with antioxidant property protects against gentamicin-induced nephrotoxicity in rats," Life Sciences, vol. 66, no. 26, pp. 2603-2611, 2000.

[30] S. K. Jain and M. Palmer, "The effect of oxygen radicals metabolites and vitamin E on glycosylation of proteins," Free Radical Biology and Medicine, vol. 22, no. 4, pp. 593-596, 1997.

[31] V. Mavichak, N. L. M. Wong, and G. A. Quamme, "Studies on the pathogenesis of cisplatin-induced hypomagnesemia in rats," Kidney International, vol. 28, no. 6, pp. 914-921, 1985.

[32] M. Khazaei, P. Bayat, A. Ghanbari, S. Khazaei, M. Feizian, A. Khodaei et al., "Protective effects of subchronic caffeine administration on cisplatin induced urogenital toxicity in male mice," Indian Journal of Experimental Biology, vol. 50, pp. 638-644, 2012.

[33] H. Luo, S. Ge, D. Yue, L. Yan, X. Xu, K. Liu et al., Effect of Vitamin E on the Development of Testis in Sheep, 2011.

[34] Y. Harima, K. Harima, T. Hasegawa, N. Shikata, and Y. Tanaka, "Histopathological changes in rabbit uterus carcinoma alter transcatheter arterial embolization using cisplatin," Cancer Chemotherapy and Pharmacology, vol. 38, no. 4, pp. 317-322, 1996.

[35] F. Maneschi, P. Benedetti-Panici, G. Scambia, M. G. Salerno, G. D'Agostino, and S. Mancuso, "Menstrual and hormone patterns in women treated with high-dose cisplatin and bleomycin," Gynecologic Oncology, vol. 54, no. 3, pp. 345-348, 1994.

[36] G. M. Rubanyi, A. D. Freay, K. Kauser et al., "Vascular estrogen receptors and endothelium-derived nitric oxide production in the mouse aorta: gender difference and effect of estrogen receptor gene disruption," Journal of Clinical Investigation, vol. 99, no. 10, pp. 2429-2437, 1997.

[37] U. C. Garg and A. Hassid, "Nitric oxide-generating vasodilators and 8-bromo-cyclic guanosine monophosphate inhibit mitogenesis and proliferation of cultured rat vascular smooth muscle cells," Journal of Clinical Investigation, vol. 83, no. 5, pp. 17741777, 1989.

[38] K.-I. Watanabe, A. Hess, W. Bloch, and O. Michel, "Expression of inducible nitric oxide synthase (iNOS/NOS II) in the vestibule of guinea pigs after the application of cisplatin," Anti-Cancer Drugs, vol. 11, no. 1, pp. 29-32, 2000.

[39] R. C. Srivastava, A. Farookh, N. Ahmad, M. Misra, S. K. Hasan, and M. M. Husain, "Evidence for the involvement of nitric oxide in cisplatin-induced toxicity in rats," BioMetals, vol. 9, no. 2, pp. 139-142, 1996.

[40] M. A. Beleh, Y. C. Lin, and R. W. Brueggemeier, "Estrogen metabolism in microsomal, cell, and tissue preparations of kidney and liver from Syrian hamsters," Journal of Steroid Biochemistry and Molecular Biology, vol. 52, no. 5, pp. 479-489, 1995. 


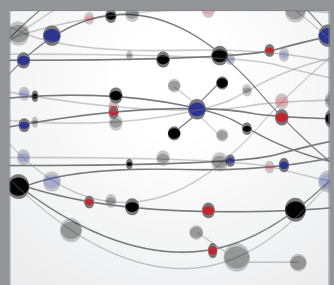

The Scientific World Journal
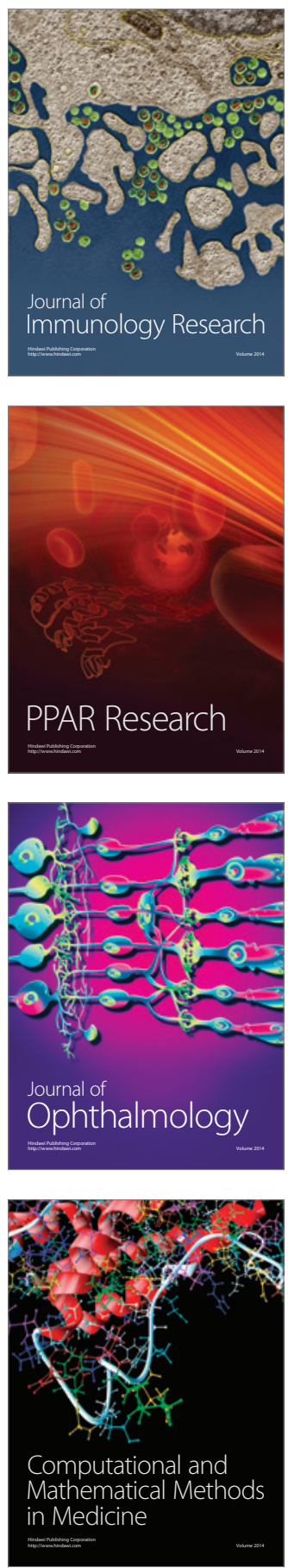

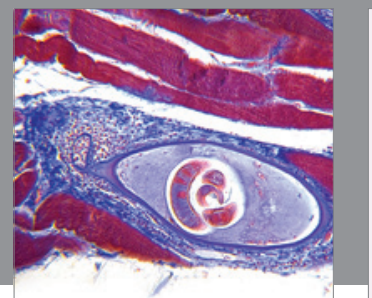

Gastroenterology

Research and Practice
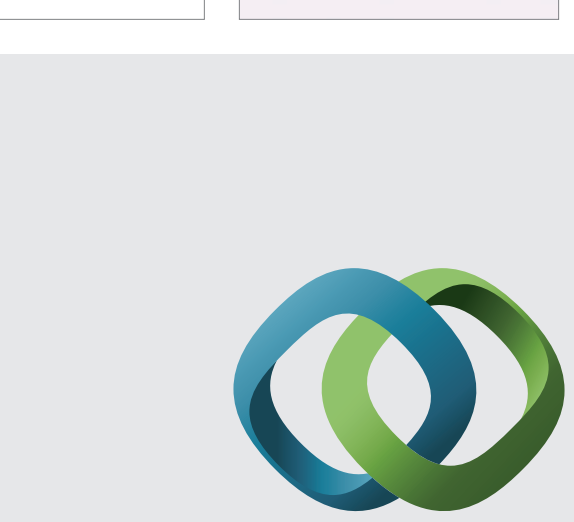

\section{Hindawi}

Submit your manuscripts at

http://www.hindawi.com
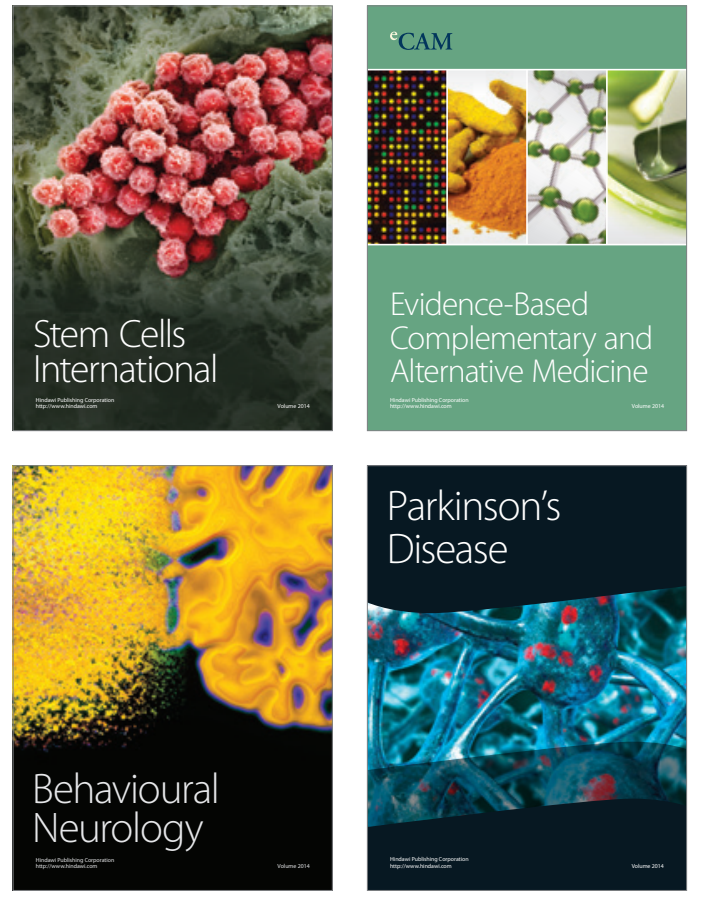
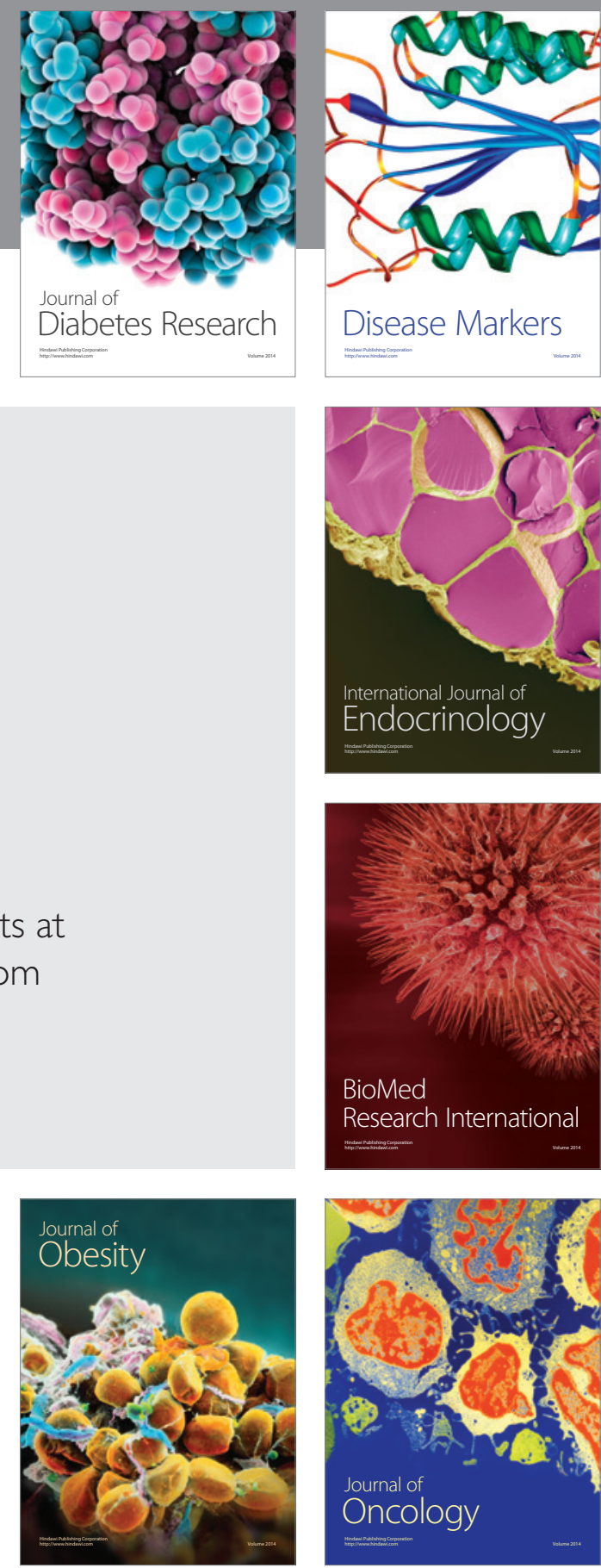

Disease Markers
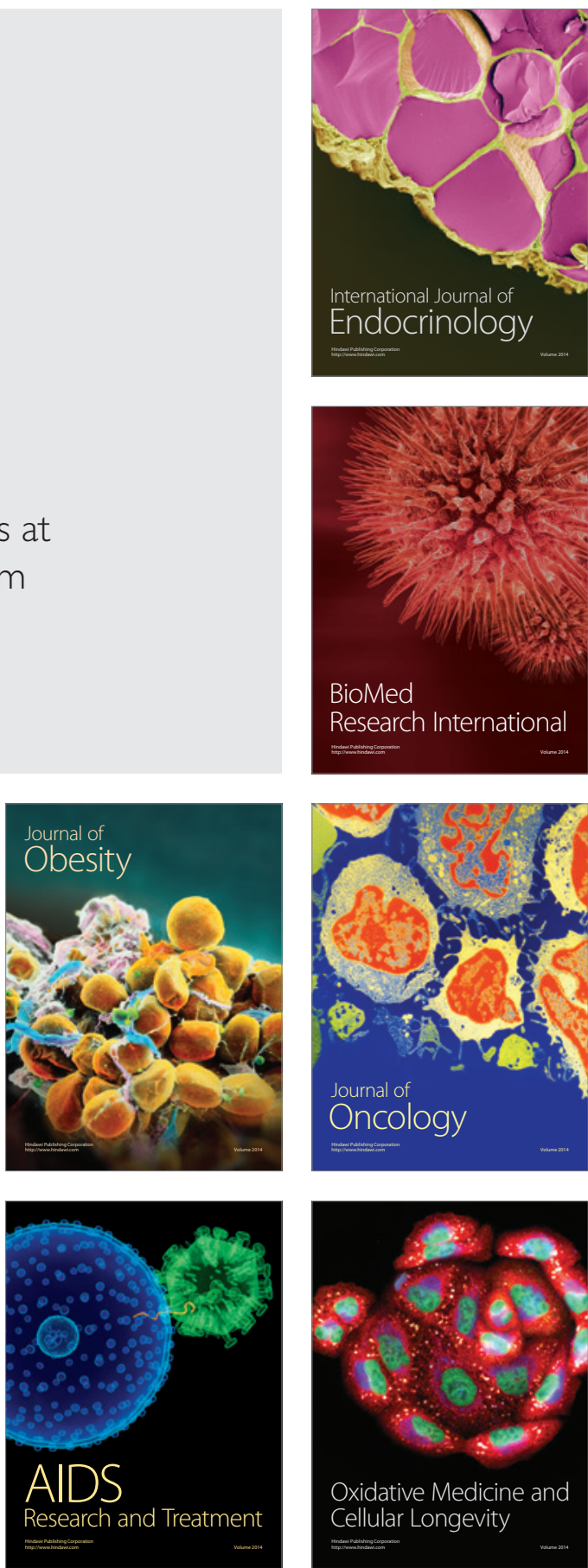